\title{
Residência na atenção básica à saúde em tempos líquidos
}

\section{| ${ }^{1}$ Eloá Rossoni |}

Resumo: A residência multiprofissional na atenção básica à saúde faz parte de uma rede de formação na área da educação e saúde no Brasil que tem sido ampliada na última década. A formação dentro de serviços de saúde tem como objetivo preparar profissionais para atuação no Sistema Único de Saúde. Este artigo analisa como trabalhadores/as e residentes vivenciavam os processos educativos no Programa de Residência Integrada em Saúde: Atenção Básica em Saúde Coletiva, desenvolvido em unidades básicas de saúde pertencentes, até 2009, ao Centro de Saúde-Escola Murialdo e vinculado à Escola de Saúde Pública do Rio Grande do Sul. Trata-se de uma investigação qualitativa com aporte nos estudos culturais em aproximação com a etnografia pós-moderna. O trabalho de campo foi desenvolvido de março de 2007 a abril de 2008, e o material empírico incluiu documentos pedagógicos e administrativos institucionais, legislação dos programas de residência, relatórios de residentes, observação das equipes e entrevistas com trabalhadores de saúde. Para refletir sobre as limitações e as possibilidades desta formação, foram utilizados, especialmente, os escritos de Bauman acerca das características culturais da "modernidade líquida", pois o contexto era marcado pela provisoriedade e pela incerteza, o que produzia potencialidades e vulnerabilidades no programa de residência.

Palavras-chave: atenção primária à saúde; residência; trabalho em equipe; modernidade líquida; Estudos Culturais.
1 Universidade Federal do Rio Grande do Sul, Faculdade de Educação, Faculdade de Odontologia, Departamento de Odontologia Preventiva e Social. Porto Alegre-RS, Brasil. Endereço eletrônico: rossonieloa@gmail.com
Recebido em: 29/04/2014 Aprovado em: 23/04/2015 


\section{Como tudo começou}

O processo investigativo que originou este artigo resultou de algumas inquietações pedagógicas e políticas em relação ao Programa de Residência Integrada em Saúde: Atenção Básica em Saúde Coletiva, desenvolvido no Centro de SaúdeEscola Murialdo e vinculado à Escola de Saúde Pública do Rio Grande do Sul (ESP-RS). Incluía-se nessas inquietações se a maneira como as condiçõos pedagógicas oferecidas nos serviços, onde a formação multiprofissional ocorria, estavam dando conta de cumprir o compromisso político de preparar profissionais para atuarem em nosso sistema de saúde.

Aproximar-se do cotidiano das equipes das unidades básicas de saúde (UBS) poderia ser uma forma de resolver essas inquietações, até porque o Centro de Saúde-Escola Murialdo vivia situações conflitantes no cenário político que implicavam a organização das equipes e repercutiam no programa de residência. Como propõe Michel Foucault (1998, p. 13): “existem momentos na vida onde a questão de saber se podemos pensar diferentemente do que se pensa, e perceber diferentemente do que se vê é indispensável para continuar a olhar ou a refletir".

O objetivo do programa de residência é formar profissionais de saúde para o planejamento, a gestão e a clínica da atenção básica, através do trabalho em equipe multiprofissional com vistas à integralidade da atenção em saúde, conforme explicitado no planejamento pedagógico elaborado em 2000, quando foi retomada a formação multiprofissional vinculada à ESP-RS (ROSSONI et al., 1999; ROSSONI; FARIAS, 2002).

A história do Murialdo como centro formador data dos anos 1970. O pioneirismo na implantação do Sistema de Saúde Comunitária e dos programas de residência médica e multiprofissional distinguiu a instituição no cenário nacional, como órgão formador na área de atenção primária à saúde (BUSNELLO, 1976; FALK, 1999; SILVA, 2002). A formação multiprofissional pós-graduada iniciou-se em 1978 - portanto, uma década antes da promulgação da Constituição Federal de 1988, que instituiu o Sistema Único de Saúde (SUS). Em 1976 era desenvolvido, no local, o Programa de Residência em Medicina Geral Comunitária, denominado atualmente Programa de Residência em Medicina de Família e Comunidade (BRASIL, 2002a). Estes acontecimentos coincidem internacionalmente com a Conferência de Alma-Ata, que discutiu os 
princípios da Atenção Primária à Saúde (APS). Alguns desses princípios foram incorporados na assistência e na formação em saúde naquela época. No país, também se iniciava o Movimento pela Reforma Sanitária, que redundou na criação do SUS na década de 80. Esses acontecimentos nacionais e internacionais articulavam-se em torno de objetivos comuns, que eram ampliar o acesso à saúde e modificar o modelo de atenção, num contexto em que as agências internacionais impunham racionalização do financiamento através de proposta de APS seletiva.

$\mathrm{Na}$ década de 90, para a implementação da descentralização da saúde - um dos princípios do SUS - ocorreram redirecionamentos nas formas de atuação das diversas esferas de gestão do sistema de saúde, cabendo ao gestor municipal a assistência à saúde local. Em 1996, quando ocorreu a municipalização da saúde em Porto Alegre, as UBS de responsabilidade da Secretaria Estadual da Saúde do Rio Grande do Sul (SES-RS) passaram para a Secretaria Municipal de Saúde (SMS), com exceção da Unidade Sanitária São José do Murialdo. A instituição reconhecida como importante local de ensino deixou de pertencer à $1{ }^{a}$ Coordenadoria de Saúde e reforçou seu vínculo com a ESP-RS, permanecendo sob a administração estadual, a fim de qualificar os processos de formação em serviço que desenvolvia (SILVA, 2002).

Desde então e até 2009, a municipalização das UBS pertencentes ao Murialdo foi assunto recorrente nas pautas do Conselho Distrital do Partenon e do Conselho Municipal de Saúde de Porto Alegre, bem como na agenda de diferentes gestóes partidárias. O fato de as UBS estarem vinculadas à gestão estadual passou a ser uma das justificativas do gestor municipal para a não ampliação de serviços de saúde na região. Como a gestão estadual investiu precariamente nas estruturas físicas das UBS, tornou-se difícil a manutenção da qualidade dos serviços oferecidos frente à demanda da população e à necessidade de ampliação da rede de atenção básica.

Em 2007, o Murialdo prestava assistência a uma população geograficamente adstrita de cerca de 50 mil habitantes, na zona leste de Porto Alegre. Possuía uma unidade central e sete UBS que estavam distribuídas nas vilas Campo da Tuca, Vargas, São Judas Tadeu, São Miguel, João Pessoa e duas no Morro da Cruz, localizadas na gerência distrital de saúde Partenon-Lomba do Pinheiro. As equipes multiprofissionais das UBS desenvolviam trabalho de assistência à população e ensino de residentes e estagiários de graduação. 
Ao longo dos anos, diversos conflitos de interesse e a pressão de várias forças políticas, corporativas e culturais determinaram diversas conformações no ensino da residência. Entre elas, destacam-se: o tempo de duração da formação multiprofissional, que variou de um a três anos; as alterações na denominação do programa (estágio, treinamento ou aperfeiçoamento especializado) e a interrupção da formação multiprofissional. Cabe ressaltar que a Residência em Medicina de Família e Comunidade não foi afetada de igual modo e teve continuidade durante o mesmo período.

A residência multiprofissional sofreu interrupção nos períodos de 19861987, em 1989-1990 e em 1996-1999, em função de diferentes conjunturas da gestão estadual de saúde. Essa suspensão ocorreu tanto devido à ausência de reconhecimento e valorização das profissōes, quanto em decorrência da diminuição do valor da bolsa de residentes das diversas profissões em relação à bolsa de residentes da Medicina, como em 1991, quando foi assinado o Decreto no 34.143 pelo governador da época (RIO GRANDE DO SUL, 1991). Esse fato só foi contornado em 2002, quando foi instituído o programa de bolsas de estudo para o Programa da Residência Integrada em Saúde (RIS) com valor igualitário para todas as profissões, através da Lei no 11.789/2002 (RIO GRANDE DO SUL, 2002a).

De 2000 a 2011, o Murialdo foi local credenciado junto à ESP-RS para o desenvolvimento do Programa de Residência Integrada em Saúde: Atenção Básica em Saúde Coletiva, e era campo de estágio para as outras três ênfases do Programa da RIS: Saúde Mental Coletiva, Dermatologia Sanitária e Pneumologia Sanitária (CECCIM; ARMANI, 2001).

Além disso, a finalidade dessa formação é atender às necessidades de preparo de profissionais para atuação no SUS e, portanto, seus princípios devem ser contemplados. Devido a essas indagações, o percurso escolhido foi o acompanhamento da formação e do trabalho das equipes das unidades básicas de saúde que eram cenários de ensino da residência. Algumas questōes mobilizaram este percurso, entre elas: como preceptores e residentes vivenciam esses processos de formação no cotidiano das Unidades Básicas de Saúde e que desafios se colocam às instâncias formadoras? 


\section{Escolhas teóricas e metodológicas}

Estamos sempre fazendo escolhas, e não poderia ser diferente em relação ao material empírico que constituiu o corpus deste artigo. As escolhas em abordar alguns aspectos em detrimento de outros são influenciadas pelas posições de sujeito que ocupo e me acompanharam em todo trabalho de campo e no momento da escrita, pois "é impossível pensar, conhecer e falar independente de agenciamentos, interesses, valores e forças sociais" (VEIGA-NETO; LOPES, 2007, p. 179).

O estudo busca compreender a complexidade dos contextos sociais e políticos em que estavam envolvidas as práticas de formação em serviço a partir do referencial teórico dos Estudos Culturais em aproximação com a etnografia pós-moderna (JOHNSON, 2006). Considerando que a cultura nos Estudos Culturais tem dupla função, sendo ao mesmo tempo objeto de estudo e local da ação e da crítica política, neste trabalho fiz algumas escolhas que considerei merecerem visibilidade.

Levando em conta que a perspectiva política que apoia e viabiliza a concretização dessa formação aponta para um compromisso com o SUS e, especialmente, com a atuação na atenção básica, procura-se visibilizar - através da análise do material empírico - as condiçôes em que esse processo formativo ocorre. Como referencial teórico, foram considerados os escritos de Bauman a respeito das características culturais da "modernidade líquida". Esse autor conceitua modernidade líquida como

\footnotetext{
[...] era líquido-moderna [...] não estabelece objetivos, nem traça uma linha terminal. Mais precisamente, só atribui a qualidade da permanência ao estado da transitoriedade. O tempo flui - não "marcha” mais. Há mudança, sempre mudança, nova mudança, mas sem destino, sem ponto de chegada e sem a previsão de uma missão cumprida. Cada momento vivido está prenhe de um novo começo e de um novo final. (BAUMAN, 2007a, p. 88).
}

Para contar essa história, usei excertos de documentos pedagógicos, dos relatórios de residentes, do regimento que orienta esta formação (RIO GRANDE DO SUL, 2002b), da legislação nacional referente à residência, dos relatos registrados na memória e no papel e o material transcrito das entrevistas. Enfim, há muitos jeitos de contá-la, depende de quem a viveu, como viveu, em que "espaço-tempo" e a partir de quais vivências culturais. Trazem-se, portanto, 
recortes das muitas histórias, visto que não é possível retratar a totalidade de processos que circulam em cotidianos que não se repetem da mesma forma, que são líquidos, fluidos e voláteis.

\section{O trabalho de campo}

Quem viaja leva na bagagem aquelas coisas que imaginamos que vamos precisar durante o percurso, "há sempre um processo de seleção do que vai compor esta bagagem. Nunca é possível carregar tudo que se tem, em mudanças e viagens" (GANDIN, 2001, p. 141). Para se inserir no campo, também é preciso precaverse com alguns detalhes, tomar informaçōes sobre o lugar, combinar a entrada, calcular o tempo do percurso, testar antecipadamente os instrumentos e levar o que é necessário, dependendo do que nos propomos a fazer. Enfim, é preciso um mínimo de organização de quem pesquisa, pois durante todo o percurso de campo é importante saber ver e ouvir, como apontam Geertz (1998) e Oliveira (1996). Para isso, precisamos criar condições. Mas que condições seriam estas na vida líquido-moderna? Oliveira (1996, p. 18) reforça que "tanto o ouvir quanto o olhar não podem ser tomados como faculdades totalmente independentes no exercício da investigação", pois estes saberes se complementam.

Nesse sentido, o que era visto e ouvido foi registrado no diário de campo, para depois ser analisado. Algumas situações chamaram minha atenção mais do que outras, e nelas investi mais tempo de escrita, até porque constituíam fatos que desconhecia sobre o funcionamento da UBS ou explicitavam conflitos sobre o processo de trabalho e da formação de residentes. Estar em campo permitiu ver risos e lágrimas, rostos de decepções e expectativas. Minha observação tornou-se participante quando eu dispunha de informações que podiam auxiliar no esclarecimento e na resolução de alguma situação da equipe, pois é quase impossível estar no campo e ficar somente observando sem participar.

Se as observaçóes provocam o envolvimento de quem pesquisa com as pessoas, com as entrevistas não foi diferente. No entanto, durante a execução das entrevistas, saber ver e ouvir pareceu mais fácil que em outros momentos, seja pela proximidade com apenas uma pessoa - e não várias - e pela possibilidade de gravar os ditos, seja pela privacidade da escuta e da cumplicidade que se instituiu entre pesquisadora e entrevistado após um período de interação no campo. Ao incluir as entrevistas no processo investigativo, considerei o caráter de complementaridade 
delas em relação às observações já mencionadas, possibilitando um "ouvir todo especial" (OLIVEIRA, 1996, p. 19) que me permitisse entender situações que não ficavam claras durante as observações das equipes. Assim, permiti que se instalasse um processo de interlocução entre pesquisadora e entrevistado, com troca de ideias e não, simplesmente, um processo de respostas a questões previamente formuladas.

Realizei as entrevistas após alguns meses de entrada em campo, com a finalidade de conhecer primeiro o funcionamento das equipes, facilitar a abordagem dos temas e propiciar a interação com os entrevistados. Antes de marcar a entrevista, era explicado aos participantes qual era o objetivo do trabalho, o tempo aproximado de cada entrevista e a necessidade de assinarem o Termo de Consentimento Livre e Esclarecido se concordassem em participar e permitissem a divulgação dos dados transcritos, conforme estabelecido no projeto de pesquisa aprovado pelo Comitê de Ética e Pesquisa da Escola de Saúde Pública do Rio Grande do Sul.

Percebi, em algumas pessoas, uma vontade de poder falar, de ser escutado e de ver valorizada sua história de vida profissional. Os entrevistados usaram, às vezes, o relato de cenas cotidianas como recurso para responder às perguntas da entrevista, contando o significado que outro colega atribuía a determinadas situações ou a forma como se comportava diante de determinado contexto.

Afirmar a oportunidade de ter escolhido a instituição ou de ter sido escolhida pelas pessoas da instituição foi um dito recorrente nas entrevistas, tanto de profissionais oriundos de outras instituições, quanto de ex-residentes que permaneceram na instituição após concluírem a formação. De alguma forma, retratou-se a importância pregressa do Murialdo enquanto cenário de ensino e assistência em APS.

A minha expectativa era grande. Para mim foi bastante prazeroso ser contratada num lugar que eu fiz residência, é uma coisa muito legal. E por eu ter feito residência aqui eu tinha o pé na realidade, então as expectativas não se frustraram porque eu fiz em cima do possível [...]. [Profissional de saúde - Entrevista em 22 de novembro de 2007].

Ao mesmo tempo, as pessoas entrevistadas mostravam-se desgostosas com os rumos dados à instituição nos últimos tempos, sentindo-se desrespeitadas, como expressa um preceptor:

Então falta respeito, respeito pela saúde, respeito pela lei [...]. Falta de respeito pelos profissionais, pela população, pelo atendimento, pela formação e burrice, porque 
poderia se abrir um polo, com pouco dinheiro. Sabe, se colocassem [dinheiro] aqui dentro, tu fazias um polo de formação e elevava o nome do governo que fizesse isso. Tenho certeza disso, porque isso aqui se enraíza para tudo quanto é lado. E nós teríamos uma respeitabilidade e temos ainda, não sei como nós conseguimos ter uma respeitabilidade no mercado [...] “Ah, tu és do Murialdo?", as pessoas sabem o que é o Murialdo. [Profissional de saúde - Entrevista em 31 de agosto de 2007].

Na UBS A, foram entrevistadas: uma das duas médicas de família, a enfermeira, uma auxiliar de enfermagem e a nutricionista, totalizando quatro trabalhadoras. Alguns fatores interferiram na decisão de entrevistar os profissionais, como o tempo de permanência e o vínculo do profissional com a equipe, a participação nas reuniões de equipe e o afastamento por problemas de saúde no período de realização das entrevistas. Na UBS B, foram entrevistados: uma das duas médicas de família, o enfermeiro, a técnica administrativa e as profissionais de odontologia, psicologia e serviço social, totalizando seis entrevistados.

A partir do material empírico, com base nos pressupostos teóricos apresentados anteriormente, abordarei a seguir o enfrentamento cotidiano das incertezas vivenciadas por trabalhadores e residentes e alguns dos desafios da formação em serviço em tempos líquidos.

\section{Enfrentando o "viveiro das incertezas"}

Quando eu voltei das férias, pensei que estava tudo tranquilo, porque eu já tinha programado tudo, eles [os residentes] estavam revoltados. Até arrumar a casa de novo e acalmar os ânimos foi muito gasto de energia. Que pena que acontece este tipo de coisa. Então, o Murialdo com todos estes problemas a gente não consegue planejar. Eu não posso planejar as coisas para um trimestre. Eu posso planejar, mas daqui uma semana ou duas pode ser que eu não tenha mais aquele profissional, tenho que remanejar toda a gente marcada. [Profissional de saúde - Entrevista em 23 de janeiro de 2008].

É emprestado de Bauman (2007a, 2007b) o título desta parte do texto, pela identificação com os contextos do trabalho de campo. Frente às observações das equipes e através da escuta dos trabalhadores, pode-se dizer, pela conjuntura que se configurava no local, que ele era o próprio "viveiro das incertezas". As mudanças que aconteceram, ao longo de um ano, na organização do trabalho nas UBS - que eram campo de formação para os residentes -, como afirma Bauman (2007b, p. 7), criaram "um ambiente novo e de fato sem precedentes para as atividades da vida individual, levantando uma série de desafios inéditos". 
Isso pode ser atribuído ao fato de que as organizações sociais não podem manter

por muito tempo uma forma estável, pois se dissolvem mais rapidamente que o tempo que levam para se constituir. A passagem da fase "sólida" da modernidade para a "líquida", como aponta o autor, impede o estabelecimento de referências para as ações humanas, bem como de estratégias de planejamento de longo prazo, pois nos remete para uma condição de provisoriedade e incerteza constante.

As coordenadoras de UBS gerenciavam a atenção à saúde de usuários e organizavam as atividades de formação em serviço dos residentes, em conjunto com os preceptores de cada profissão. Exercer a coordenação das equipes exigia certo malabarismo, como pude constatar durante as observações nas equipes e como explicitou um dos entrevistados com relação à ambivalência suscitada, quando as demandas são maiores do que a capacidade ou as condiçôes que tinham para resolvê-las:

Ah! Eles dizem "vocês têm autonomia para resolver e decidir", ao mesmo tempo em que não temos condições de decidir, nem resolver. Acho que começa por aí. Por sua vez a coordenação da equipe também fica a mercê duma estrutura que está deste jeito, que está capenga. Por exemplo, insumo, medicação é uma coisa que, outro dia eu estava comentando, daqui a nove meses o que vai ter de criança, porque anticoncepcional faltou, primeiro faltou injeção e agora o comprimido já faz um tempão. O próprio preservativo está em falta. [Profissional de saúde - Entrevista em 31 de agosto de 2007].

Em geral, as coordenações eram profissionais da Medicina convidados, pela direção da instituição, para exercer a gerência a cada troca de gestão. O fato de a categoria médica, majoritariamente, estar ocupando essa posição de sujeito deveu-se ao grande movimento corporativo iniciado, no Brasil, a partir do Ato Médico (BRASIL, 2002b), que, entre outras coisas, propôs que o profissional da medicina é quem deveria responder tecnicamente pelos serviços de saúde. Apenas uma das sete UBS mantinha outro profissional de saúde na coordenação. Até 2004, profissionais de enfermagem, psicologia e nutrição também exerciam esta função. No entanto, a ausência de gerentes formais em outras UBS parecia depender de inúmeros fatores, entre eles a não remuneração pela atividade de coordenação, a instabilidade institucional e a dificuldade de lidar no cotidiano com a incerteza.

As coordenadoras das UBS podem ser denominadas gerentes da provisoriedade. Utilizo essa expressão, pois são tantas mudanças, intempéries e decisões, que 
devem enfrentar a cada dia, semana e mês, que me parece ser o que caracteriza melhor a posição/função exercida nas UBS, como comenta uma das entrevistadas:

Acho que a própria situação dessa confusão toda não favorece que tenha uma maior organização. A gente não consegue formar uma equipe, cada hora está afunilando, sai gente daqui, puxa dali, empurra de lá, é muito difícil fazer um trabalho funcionar com tanta mudança e confusão, as pessoas precisam de uma estabilidade pra funcionar bem. [Profissional de saúde - Entrevista em 2 de abril de 2008].

Tudo tem vida curta. Com frequência, os trabalhadores eram deslocados de uma equipe para outra, para cobrir o colega que fora demitido, transferido, estava em férias e/ou que adoecera. Reclamavam que assim era difícil manter vínculo com outros trabalhadores, com residentes e usuários. Muitos adoeciam e sofriam com as condiçôes de trabalho, disse uma técnica de enfermagem que trabalhara em outras unidades do Murialdo: "Duas das minhas colegas já entraram em licença-saúde com problemas emocionais". Essas observações aproximavamse das constatações de Bauman sobre as exigências da "vida líquido-moderna". Como está explicitado a seguir, é demandada aos indivíduos:

[...] a responsabilidade em resolver os dilemas gerados por circunstâncias voláteis e constantemente instáveis e jogada sobre os ombros dos indivíduos - dos quais se espera que [...] suportem plenamente as consequências de suas escolhas. [...] A virtude que se proclama servir melhor aos interesses do indivíduo não é a conformidade às regras $[. .$.$] mas a da flexibilidade: a prontidão a mudar repentinamente$ de táticas e de estilo, abandonar compromissos e lealdades sem arrependimento. (BAUMAN, 2007b, p. 10).

Pelos relatos de entrevistados, verificava-se que as pessoas não estavam, na maioria das vezes, preparadas para lidar com isso. Poderia dizer que não era possível desenvolver trabalho em equipe ou formar residentes para o trabalho em equipe com as incertezas presentes no cotidiano desses serviços. Penso que o desafio seja entender que modalidades de ação os trabalhadores e residentes criavam/inventavam e quais resistências utilizavam para fazer frente a essa provisoriedade constante, a esse não saber para onde ir, a municipalização que não acontecia, mas estava sempre presente como uma possibilidade. Como desenvolver a RIS, enquanto estratégia para formação de profissionais para o SUS, com essa perspectiva de vida curta e insuficiente para realização de projetos coletivos?

A precariedade dos contratos de profissionais com fundaçôes que sustentavam parte das atividades de preceptoria e assistência das equipes, principalmente no que se referia à Residência em Medicina de Família e Comunidade, era 
incongruente com a política nacional de incentivo à consolidação e à expansão

da ESF, que carece de profissionais com residência nessa área. Um exemplo dessa precariedade ocorreu no início de 2007, momento em que ingressava uma nova turma de residentes, quando os sete médicos de família contratados por uma fundação para preceptoria foram demitidos. Como as direçôes e as coordenações do Murialdo e ESP-RS explicitaram para o gestor estadual que isso inviabilizaria o início da residência, os profissionais tiveram seu aviso prévio suspenso e continuaram trabalhando nas equipes. Apenas três dos sete preceptores permaneceram, pois alguns profissionais optaram por pedir demissão frente à proposta de outros empregos estáveis.

A coordenadora de uma das UBS relatou a dificuldade que vinha enfrentando com as inúmeras perdas de profissionais como um dos fatores limitantes do trabalho em equipe para a formação de residentes:

$\mathrm{O}$ que eu acho que temos como limite é a flutuação de pessoas. Quando você consegue fazer os contratos bem certinhos, as pessoas saem de lá. E aí você tem de começar tudo do zero de novo. [...] A MFC era contratada para preceptoria através da FAURGS e recebeu aviso prévio três vezes. Ela fez processo seletivo alguns anos atrás em outra instituição. Chamaram-na para assumir o posto onde ela fez a formação e próximo da casa dela. Ela me disse: "Eu não tenho garantia nenhuma que o mês que vem eu não vou ter aviso prévio de novo. Vou para um lugar que eu vou gastar menos. Viver nesta instabilidade também é horrível”. Para a equipe foi muito traumático e daí começou a sair um atrás do outro. [Profissional de saúde - Entrevista em 23 de janeiro de 2008].

"Começar tudo do zero de novo" parece uma prerrogativa dos tempos líquidos. A médica de família e comunidade de uma das UBS permaneceu. Ela lembrou as demissões com preocupação, dizendo o quanto a instabilidade torna difícil a manutenção de vínculos e imprime uma perspectiva de curto prazo no planejamento individual e coletivo, provocando incerteza, a qual é considerada como o mal-estar cultural característico da pós-modernidade (BAUMAN, 1998).

Eu estava pensando hoje. Agora vem dezembro, termina janeiro será que vem outro aviso prévio? É muito ruim. Atualmente, eu tenho outro trabalho, e fica um pouquinho melhor. Mas antes eu trabalhava só aqui e eu tenho filho pequeno. Sabe quando tu te preparas, planeja assim, aí vem uma facada. É uma instabilidade muito ruim. Aí tu vais criando vínculo e não sabes até quando vai durar. [Profissional de saúde - Entrevista em 22 de novembro de 2007].

Como aponta Bauman (1998, p. 221), “a incerteza concentrada na identidade não precisa nem das benesses do paraíso, nem da vara do inferno para causar 
insônia. Está tudo ao redor [...] em laços humanos assumidos até segunda ordem, em empregos que podem ser subtraídos sem qualquer aviso". Na entrevista realizada, com outro membro da mesma equipe, isso foi apontado também:

Eu tenho procurado ajudar, na medida do possível, a questão de residentes, tenho participado das atividades. Aí veio toda aquela questão da municipalização, da demissão da MFC, já foi demitida umas três ou quatro vezes, reingressa e vem de novo o aviso prévio. Então, é um estresse muito grande, mas eu tenho que te dizer, ao longo desses anos, aprendi tanta coisa [...] Às vezes tem umas coisas que extrapolam os limites da gente, mas eu aprendi tanta coisa, aprendi a ser tão político, aprendi a dialogar, aprendi a fazer consenso, a negociar, às vezes eu não me conheço. [Profissional de saúde - Entrevista em 31 de agosto de 2007].

O preceptor salienta que lidar com essas incertezas tem sido uma aprendizagem, pois desenvolve as capacidades de ser político, dialogar, fazer consenso e negociar. Aos residentes e trabalhadores que permaneceram nos serviços, cabe esse exercício constante de lidar com as incertezas e desenvolver a capacidade de sobrepô-las. Cada um dos profissionais que buscou outros caminhos - saindo do emprego estadual, buscando transferência para outra instituição dentro do próprio Estado ou garantindo que o rendimento mensal viesse também de outro emprego procurou de alguma forma minimizar os efeitos decorrentes dessas incertezas. Percebe-se que "os medos estimulam as pessoas a assumirem uma ação defensiva" (BAUMAN, 2007b, p. 16). Como as perspectivas de vida se apoiam em terrenos instáveis, em geral as pessoas concentram seus esforços nas coisas que podem influenciar, procurando reduzir o risco da incerteza do futuro.

Apesar de estarem vulneráveis às provisoriedades, residentes e trabalhadores encontravam brechas para atitudes solidárias, como relatou a coordenadora da UBS A, em relação ao apoio que recebeu de residentes de segundo ano, diante da saída de profissionais da equipe:

Então, esta equipe que tenho hoje, as residentes são muito unidas. Ou racha ou gruda e elas graças a Deus que se grudaram. É tão interessante, pois como R2 elas dividiram $\mathrm{o}$ ano para fazer gerenciamento e nesse intervalo em que eu não tenho R2 em gerenciamento, elas se dividiram em duplas para fazer alguma coisa próxima da gerência. Para me ajudar elas ficaram com algumas incumbências que elas vão fazer para que eu não me estresse [...] Elas tomaram esta iniciativa. Para não deixar cair a peteca. Isto é, claro, mérito delas, mas é um pouco das coisas que elas veem a gente fazendo. Isto é muito legal. [Profissional de saúde - Entrevista em 23 de janeiro de 2008].

Solidariedade implica ação para tornar melhor aquilo que não está bom e/ou para ajudar quem não está bem e/ou ainda ocasiona, em tempos líquidos, não 
deixar as coisas piorarem. Não basta apenas desejar a melhora de uma situação ou ser tolerante com ela - é preciso envolver-se com o que está ocorrendo. A transformação da tolerância em solidariedade acarreta o "reconhecimento da penúria e sofrimentos de outras pessoas como responsabilidade própria de alguém, e o alívio, assim como, subsequentemente, a eliminação da penúria como a tarefa própria de alguém" (BAUMAN, 1998, p. 82). Nos primeiros meses de formação, uma residente expôs a importância da cooperação para enfrentar as dificuldades que surgem no cotidiano:

Ressalto a cooperação, o respeito, o carinho e a dedicação da equipe como um todo neste período inicial de três meses, em que enfrentamos algumas situações difíceis, principalmente no mês de março, quando ficamos sem a presença de uma coordenadora, visto que a substituta da mesma [que estava de férias] foi afastada da equipe [a profissional foi demitida, como foi explicitado pela residente, mesmo exercendo o papel de coordenadora à época]. [Residente $\mathbf{E}$. Relatório $1^{\circ}$ trimestre do primeiro ano - maio de 2007].

Nesse sentido, o envolvimento dos residentes com os usuários e com a equipe em que atuavam é uma das possíveis resistências ao ambiente líquido-moderno. A população dos territórios vinculados às UBS crescera ao longo dos anos, enquanto que o número de profissionais diminuíra e as UBS, tanto as construçôes próprias do Estado como as casas de dois pisos alugadas, não tinham sido ampliadas; apenas sofreram reformas ou foram deslocadas em virtude da violência local.

O estado de permanente precariedade das condições de trabalho nas unidades, aliado à incerteza sobre o futuro institucional e à opressiva situação de insegurança do presente - devido à demanda de usuários por atenção exceder ao que a equipe podia propiciar -, tornava instável o cotidiano dessas equipes. Se, em outros tempos, o trabalho podia ser visto como uma vocação ou uma missão, por proteção ou não, essas condições estimulavam o desengajamento de trabalhadores, que expressavam em suas falas um sentimento de abandono do gestor estadual, por não tomar posições frente à necessidade de redefinir o papel da instituição, conforme é transcrito a seguir:

É um investimento que te mantém no governo, seja no governo do estado ou do município. Eu não consigo entender, sinceramente. Aí o Estado quer se livrar do Murialdo e faz um pacto com o Município. Mas tu não pode simplesmente extinguir um serviço como esse, que é de capacitação. A gente sabe e tem exemplo disso, dos nossos residentes que saíram daqui e assumiram cargos e funçōes, em concursos, o pessoal sai qualificado daqui, mesmo com as dificuldades que a gente tem, mesmo com a escassez que nós temos de preceptores, eles saem com uma bagagem daqui, 
porque os que ficam pelo menos ficam segurando e fazem acontecer, então a falta de iniciativa, a falta de injeção de recursos é algo que eu não consigo entender, porque fazem isso. "Ah, porque eles querem privatizar a saúde pública" [...]. [Profissional de saúde - Entrevista em 31 de agosto de 2007].

Frente ao quadro descrito, trago algumas reflexões de Bauman, que me permitiram entender o contexto cultural em que o campo estava inserido, referente à separação entre o poder do Estado e a política, da qual

[...] se esperava, desde o surgimento do Estado Moderno e até muito recentemente, que compartilhasse as funções do Estado Nação. Entre ambos, os dois resultados inter-relacionados desse divórcio obrigam ou encorajam os órgãos do Estado a abandonar, transferir ou [...] subsidiar e terceirizar um volume crescente de funções que desempenhavam anteriormente. Abandonadas pelo Estado, essas funçôes se tornam um playground para as forças do mercado, notoriamente volúveis e inerentemente imprevisíveis e/ou são deixadas para a iniciativa privada e aos cuidados dos indivíduos. (BAUMAN, 2007b, p. 8).

Nos setores de educação e saúde, a presença de inúmeros trabalhadores com contratos provisórios terceirizados tem sido comum, provocando instabilidade no campo estudado, tanto na residência quanto na assistência. $\mathrm{O}$ estudo da gestão local de dois municípios do Rio Grande do Sul, realizado por Protti, Marques e Righi (2004, p. 221), refere que "a estruturação da rede básica a partir do Programa de Saúde da Família tem promovido o desenvolvimento de uma rede sustentada na terceirização", que era o que vinha ocorrendo no município de Porto Alegre.

Em relação ao papel do Estado, Bauman (2007a, 2007b) também atribui à perda de valor da ação coletiva a retração ou redução gradual da segurança endossada pelo Estado, afirmando que:

Os laços inter-humanos, que antes teciam uma rede de segurança que dependiam de investimento de tempo e esforço e valiam o sacrifício de interesses individuais imediatos [...], se tornam cada vez mais frágeis e reconhecidamente temporários. A exposição dos indivíduos ao capricho dos mercados de mão de obra e de mercadorias inspira e promove a divisão e não a unidade. Incentiva atitudes competitivas, ao mesmo tempo que rebaixa a colaboração e o trabalho em equipe à condição de estratagemas temporários que precisam ser suspensos e concluídos no momento em que se esgotarem seus benefícios. (BAUMAN, 2007b, p. 8-9).

Nesse sentido, Bauman analisa as consequências trazidas pela provisoriedade constante, que acarreta precariedade nas conformações de instituições, serviços, programas e nas nossas vidas. 
O colapso do pensamento, do planejamento e da ação por longo prazo, e o enfraquecimento das estruturas sociais nas quais estes poderiam ser traçados com antecedência, leva a um desmembramento da história política e das vidas individuais numa série de projetos e episódios de curto prazo [...]. Cada passo seguinte deve ser uma resposta a um diferente conjunto de oportunidades e a uma diferente distribuição de vantagens, exigindo assim um conjunto diferente de habilidades e um arranjo diferente de ativos. (BAUMAN, 2007b, p. 9).

Tem sido apontado que a formação de profissionais de saúde é um dos nós críticos para implementação do SUS (CECCIM; CAPAZZOLO, 2004). Entretanto, a discussão da precariedade do trabalho no SUS não é um problema menos relevante, como pude observar neste trabalho e diante da conjuntura nacional. Em 2003, o Ministério da Saúde (MS) criou o Comitê Nacional Interinstitucional de Desprecarização do Trabalho no SUS (BRASIL, 2003). De lá para cá, diversos documentos divulgaram esse processo, ainda com pouca repercussão no quadro nacional. Um dos documentos escritos pelo Conselho Nacional de Secretários de Saúde (CONASS) apontava as principais causas para o problema (BRASIL, 2004), dentre as quais: a Lei de Responsabilidade Fiscal e os limites de gasto com pessoal; as dificuldades de realização de concurso público; a lentidão na reposição, substituição e/ou ampliação de trabalhadores; falta de vontade política dos gestores nas diversas esferas de governo para regularizar essa demanda, inviabilizando expansão de ações na saúde, sobretudo na Atenção Primária. A inexistência de Planos de Cargos, Carreiras e Salários, que contemplem as especificidades de vínculos, cargos e carreiras, a avaliação de desempenho e a remuneração adequada também contribuem para o agravamento da precarização do trabalho no SUS.

O documento elaborado pelo CONASS enfatizava em seu texto que "a gestão do trabalho na saúde encontra-se engessada pela regulação rígida do emprego público", aliada à "excessiva precarização dos vínculos empregatícios" (BRASIL, 2004). Esses aspectos afetavam de igual modo o quadro de trabalhadores das UBS do Murialdo.

Em outra cartilha do CONASS sobre a gestão do trabalho no SUS, discute-se que a precariedade do trabalho em saúde parece não estar ligada diretamente ao desemprego, visto que o próprio SUS é "um forte indutor de empregos" (BRASIL, 2007). É apontada como preocupante a heterogeneidade de vínculos nesse conjunto de transformações, pois o sistema de saúde brasileiro vem incorporando 
a terceirização dos serviços em números e formas diferentes nas diversas esferas de governo. Segundo Amâncio Filho (2004, p. 376):

[...] a globalização vem implicando mudanças econômicas, sociais, políticas e culturais. Para enfrentar a nova divisão internacional do trabalho, políticas de corte neoliberal propõem mudanças em relação ao tamanho e às atribuições do Estado, advogam a desregulamentação das economias nacionais, enfatizam o papel do mercado e adotam um amplo programa de privatizaçōes na esfera pública, incluindo áreas tradicionais de atuação, como educação e saúde, para reduzir os gastos estatais.

Quanto ao envolvimento de profissionais de saúde do Murialdo com a preceptoria de residentes e de alunos de graduação, é importante considerar que estes não tinham acesso às bolsas de preceptoria - propostas, em 2005, para os programas de residência financiados pelo MS - por se tratar de programa estadual que garante somente bolsas de residentes. As bolsas do MS visavam estimular a incorporação da função de preceptoria de residentes e discentes de cursos de graduação por profissionais que realizavam assistência nos serviços públicos de saúde, via repasse de verba do Governo Federal para os programas de formação (Programas de Residência financiados pelo MS, Pró-Saúde e PET-Saúde). Nas UBS do Murialdo, a carga horária de preceptoria era computada dentro da carga horária de trabalho.

Os vínculos precários e a rotatividade das equipes são aspectos detectados em vários estudos, entre eles o que foi realizado por Conill (2008) sobre a implantação da ESF em Florianópolis. Essa autora analisou a atenção primária, enquanto política de reforma setorial, e detectou deficiências no acesso (relação inadequada entre equipe e número de famílias) e na integralidade da atenção à saúde (problemas na referência para especialidades). Constata-se que as dificuldades enfrentadas nas UBS do Murialdo são partilhadas em outros serviços e em outros "espaços-tempos" de formação no país.

Quanto aos cenários e às pessoas que participaram deste estudo, muitas mudanças aconteceram depois de 2008. Os residentes que faziam sua formação nesses locais se encontram atuando em outros espaços de ensino, assistência e gestão, e alguns inclusive atuam como preceptores de programas de residência. As composições das equipes das UBS observadas mudaram radicalmente após a municipalização, que ocorreu em 2009, e poucas pessoas entrevistadas permaneceram nas equipes em que atuavam. Os residentes que hoje vivenciam 
os processos educativos nessas UBS - e em outras unidades de Estratégia de

Saúde da Família que passaram a compor os campos de formação, tendo em vista a descentralização do programa ocorrida a partir de 2011 para Sapucaia do Sul, Esteio e Venâncio Aires - estão experimentando outras possibilidades, sendo algumas delas diversas daquelas discutidas neste artigo. No entanto, o problema da precariedade do trabalho devido à provisoriedade dos contratos profissionais de trabalhadores permanece. Em 2012 e 2013, ocorreu de residentes terem mais tempo nas equipes que alguns de seus preceptores, pois esta rotatividade se manteve, não somente em Porto Alegre, mas em outros municípios que são cenários desta formação.

\section{Considerações finais}

Por ter estado lá, escrevo aqui as reflexões que, por ora, são possíveis. Saliento que a provisoriedade e a incerteza foram características marcantes do "espaçotempo" observado, provocando insegurança e dificuldade de planejamento das atividades de formação e assistência. As pessoas que vivenciaram as dificuldades e os desafios no cotidiano das UBS, cada uma à sua maneira, aprenderam a lidar com elas. Algumas pessoas ficaram e lutaram, outras resolveram seguir outro caminho ou simplesmente assistiram o que acontecia. Apesar de sofrerem com a provisoriedade, a incerteza e a insegurança, os trabalhadores e residentes desenvolveram diversas formas de resistência e criatividade no cotidiano das equipes, o que possibilitou que aprendessem no e com o coletivo.

Temos, assim, um impasse, se o desejo é formar profissionais de saúde que coloquem em prática os principais atributos da APS/ABS, que são: o vínculo, a longitudinalidade, a integralidade da atenção e a coordenação do cuidado. Eis a questão: como fazer os residentes considerarem esses atributos com equipes de saúde provisórias e com a insegurança de continuidade de projetos coletivos?

Outras questôes permeiam o tema da formação multiprofissional em saúde. Nos últimos dez anos, ocorreu maior investimento nessa formação, com o objetivo de atender às demandas de trabalhadores para os serviços de saúde, de forma que se adequassem às diretrizes e aos princípios do SUS, em especial para prepará-los para o trabalho em equipe e para a integralidade da atenção à saúde. Com essa formação, há o desejo de produzir uma identidade cultural 
com o compromisso de "afirmação da vida", com a proposta do SUS, que inclui o direito à saúde. Assim, os documentos pedagógicos examinados apontavam para uma formação com centralidade no usuário, embora as condições líquidomodernas dificultassem o cumprimento desse quesito.

A repetida questão de o trabalho na ABS/APS ser considerado de baixa complexidade e se atribuir pouca ou nenhuma valorização a quem a ele se dedica também se fazia presente no "espaço-tempo" dessa formação. Contudo, a questão vem acompanhada de outras problematizações, entre elas, a de como se dá essa escolha e que condiçóes permitem que ela se mantenha. O contato de alunos com os serviços de atenção básica através de estágios ou vivências na graduação e pós-graduação são alguns fatores que parecem interferir nisso. Assim, as atuais políticas nacionais de educação e saúde investem na inserção de discentes da graduação na ABS/ESF, ao apostar na possibilidade de que conhecer e vivenciar constituem passos importantes para uma futura escolha.

O reconhecimento nacional do Murialdo como centro de formação na atenção básica e sua história não deram conta de sustentar as propostas de investimento nas unidades básicas de saúde e na contratação e manutenção de trabalhadores junto à gestão estadual naquele período. A memória parece algo inútil na "modernidade líquida", em que prevalece uma cultura de desvinculação, descontinuidade e esquecimento. Entretanto, para não cairmos no pessimismo, convém lembrar que apesar das dificuldades explicitadas, a solidariedade e a resistência marcavam o cotidiano dessa formação. Para que a escolha pela atuação na atenção básica permaneça após concluída a formação, é necessário qualificar as estruturas físicas e os processos de trabalho dos serviços, revendo a forma de contratação dos profissionais de saúde, a fim de que tenham estabilidade, plano de carreira e remuneração adequada. Tarefa que se torna difícil, quando são elaborados projetos de leis que reforçam a terceirização dos serviços e protegem cada vez menos os direitos dos trabalhadores.

\section{Agradecimento}

Agradecimento especial à Profa. Dra. Dagmar Estermann Meyer, pela orientação na tese de doutorado do PPG da Faculdade de Educação, UFRGS, que originou este artigo. 


\section{Referências}

AMÂNCIO FILHO, A. Dilemas e desafios da formação profissional em saúde. Interface Comunicação, Saúde, Educação. Botucatu, v. 8, n. 15, p. 375-80, mar./ago. 2004.

BAUMAN, Z. O mal-estar da Pós-Modernidade. Rio de Janeiro: Jorge Zahar, 1998. . Vida líquida. Rio de Janeiro. Jorge Zahar, 2007a. . Tempos líquidos. Rio de Janeiro: Jorge Zahar, $2007 \mathrm{~b}$.

BRASIL. Resolução n. 1, de 14 de maio de 2002. Dispõe sobre o programa de Residência Médica em Medicina de Família e Comunidade entre as especialidades médicas credenciáveis pela CNRM. Diário Oficial da União, Brasília, 15 mai. 2002a.

BRASIL. Projeto de Lei do Senado no 25/2002. Define o Ato Médico e dá outras providências, 2002b. Disponível em: http://www.senado.gov.br/atividade/materia/detalhes.asp?p_cod_ mate $=49554$. Acesso em: 24 jun. 2009.

. Ministério da Saúde. Portaria n. 2430/GM, de 23 de dezembro de 2003. Cria o Comitê Nacional Interinstitucional de Desprecarização do Trabalho no SUS. Diário Oficial da Uniāo, Brasília, 26 dez. 2003, seção 1, p. 26. Disponível em: <http://portal.saude.gov. br/portal/arquivos/pdf/portaria_2430_sgtes_26122003.pdf>. Acesso em: 24 jun. 2009.

. Conselho Nacional de Secretários de Saúde (CONASS). Recursos humanos: um desafio do tamanho do SUS. Brasília: CONASS, 2004.

Conselho Nacional de Secretários de Saúde. Gestão do Trabalho na Saúde / Conselho Nacional de Secretários de Saúde. - Brasília: CONASS, 2007. 116 p. (Coleção Progestores - Para entender a gestão do SUS, 5).

BUSNELlO, E. A. D. A integração da saúde mental num Sistema de Saúde Comunitária. Tese (Habilitação à livre docência em Psiquiatria) - Faculdade de Medicina, Universidade Federal do Rio Grande do Sul, Porto Alegre, 1976.

CECCIM, R. B.; ARMANI, T. B. Educação na Saúde Coletiva: papel estratégico na gestão do SUS. Divulgação em saúde para debate. Rio de Janeiro, v. 23, p. 30-56, 2001.

; CAPOZZOLO, A. A. Educação dos profissionais de saúde e afirmação da vida: a prática clínica como resistência e criação. In: MARINS, J. J. N. et al. (Org.). Educação médica em transformação: instrumentos para a construção de novas realidades. São Paulo: Hucitec, 2004. p. 346-390.

CONILL, E. M. Ensaio histórico-conceitual sobre a Atenção Primária à Saúde: desafios para a organização de serviços básicos e da Estratégia Saúde da Família em centros urbanos no Brasil. Cadernos de Saúde Pública. Rio de Janeiro, v. 24, sup. 1, p. s7-s27, 2008.

FALK, J. W. Aspectos conceituais, históricos e curriculares da Medicina Geral Comunitária. In: LEITE, DBC. (Org.). Pedagogia Universitária: conhecimento, ética e política no ensino superior. Porto Alegre: EdUFRGS, 1999. p. 159-180. 
FOUCAULT, M. O uso dos prazeres. In: FOUCAULT, M. História da Sexualidade. Rio de Janeiro: Graal, 1998, v. 2, p.13.

GANDIN, L. A. Reseña de "Identidades traduzidas: cultura e docência teutobrasileiroevangélica no Rio Grande do Sul" de Dagmar Estermann Meyer. Revista Brasileira de Educação. São Paulo, n. 18, p.140-143, set./dez. 2001.

GEERTZ, C. A interpretação das culturas. Rio de Janeiro: Guanabara Koogan, 1998.

JOHNSON, R. O que é, afinal, Estudos Culturais? In: JOHNSON, R.; ESCOSTEGUY, A. C.; SCHULMAN, N. (Org.). O que é, afinal, Estudos Culturais? 3. ed. Belo Horizonte: Autêntica, 2006. p. 7-133.

OLIVEIRA, R. C. O Trabalho do antropólogo: olhar, ouvir, escrever. Revista de Antropologia. São Paulo, v. 39, n. 1, p. 13-37, 1996.

PROTTI, C. A.; MARQUES, J.; RIGHI, L. B. Gestão Local de Saúde: descentralização e desenvolvimento institucional da saúde em dois municípios do estado do Rio Grande do Sul, Brasil. In: MISOCZKY, MC; BORDIN, R (Org.). Gestão local em saúde: práticas e reflexões. Porto Alegre: Dacasa, 2004, p.217-236.

RIO GRANDE DO SUL. Decreto no 34.143. Dispõe sobre o valor da bolsa de estudos paga aos bolsistas não médicos do Hospital Psiquiátrico São Pedro e Unidade Sanitária São José do Murialdo, e estabelece o sistema de reajuste. Diário Oficial do Estado, Porto Alegre, 30 dez. 1991.

. Secretaria de Saúde do Rio Grande do Sul. Lei no 11.789, de 17 de maio de 2002. Cria, no âmbito da Secretaria da Saúde do Rio Grande do Sul, o programa de bolsas de estudo para o Programa de Residência Integrada em Saúde. Boletim da Saúde, Porto Alegre, v. 16, n. 1, p. 193, 2002a.

. Secretaria de Saúde do Rio Grande do Sul. Portaria no 71/2002, de 24 de dezembro de 2002. Aprova o Regulamento do Programa de Residência Integrada em Saúde. Boletim da Saúde, Porto Alegre, v. 16, n. 1, p. 193, 2002 b.

ROSSONI, E. et al. Residência Integrada em Saúde Coletiva. In: MOSTRA NACIONAL DE PRODUÇÃO EM SAÚdE DA FAMÍlIA: CONSTRUINDO UM NOVO MODELO, 1., 1999, Brasília. Resumos de trabalhos... p. 46-47.

; FARIAS, E. R. O processo de ensino-aprendizagem da Residência Integrada em Saúde: Atenção Básica em Saúde Coletiva. Boletim da Saúde. Porto Alegre, v. 16, n. 1, p. 175-176, 2002.

SILVA, C. H. da. Murialdo: história e construção na Saúde Coletiva do Rio Grande do Sul. Boletim da Saúde. Porto Alegre, v. 16, n. 2, p. 105-115, 2002.

VEIGA-NETO, A.; LOPES, M. C. Identidade, cultura e semelhanças de família: as contribuições da virada linguística. In: BIZARRO, R (Org.). Eu e o outro: estudos multidisciplinares sobre identidade, diversidade e práticas culturais. Porto: Areal, 2007. 


\section{Residency at the primary health care in liquid times}

The multi-professional residence at the primary health care is part of a network of training in education and health in Brazil that has been expanded in the last decade. Training within health services aims to prepare professionals to work in the Health National System. This article examines how workers and residents experience educational processes in the Program of Integrated Health Residency: Primary Care in Public Health, developed in basic health units belonging, up to 2009, to the Murialdo Health School-Center, and linked to Rio Grande do Sul School of Public Health. This is a qualitative research whose methodological course has input into cultural studies in approach to post-modern ethnography. The fieldwork was conducted from March 2007 to April 2008 and empirical data included educational and administrative documents institutions, relevant legislation to the regulation of residency programs, reports of residents, direct observation of teams and interviews with health workers. To reflect on the limitations and possibilities of this training, the writings of Bauman about the cultural characteristics of "liquid modernity" were used, because the context was marked by tentativeness and uncertainty, which produce potentialities and vulnerabilities in the residency program.

> Key words: Primary Health Care; residency; team work; liquid modernity; Cultural Studies. 